\title{
DETERMINATION OF SUPEROXIDE DISMUTASE ACTIVITY WITH AN ELECTROCHEMICAL OXYGEN PROBE
}

\section{MOSCONE}

Dipartimento di Scienze e Tecnologie Chimiche II, Universita' di Roma, Tor Vergata, 00173 Roma (Italy)

\section{MASCINI*}

Istituto de Chimica Analitica, Universita' di Firenze, 50121 Firenze (Italy)

(Received 22nd October 1987)

\section{SUMMARY}

A flow system is described for measurements of superoxide dismutase activities over wide concentration ranges by varying the substrate, $\mathrm{pH}$ and flow conditions. Pyrogallol and 6-hydroxydopamine were the best substrates found; the limits of detection were $1.5 \times 10^{-9} \mathrm{M}$ superoxide dismutase at $\mathrm{pH} 9.5$ and $2 \times 10^{-10} \mathrm{M}$ at $\mathrm{pH} 7.4$, respectively. Epinephrine was less suitable; catechol was not useful. Epinephrine provided good sensitivity at $\mathrm{pH} 10$ when a residence time of 8 min in the system was allowed, but the measurements were then less reproducible than with pyrogallol or 6-hydroxydopamine.

Superoxide dismutases are a class of metalloenzymes that are present in all oxygen-consuming living cells and protect organisms by controlling the concentration of superoxide ion $\left(\mathrm{O}_{2}^{-}\right)$in the cell, because they accelerate the rate of the reaction

$$
2 \mathrm{O}_{2}^{-}+2 \mathrm{H}^{+}=\mathrm{H}_{2} \mathrm{O}_{2}+\mathrm{O}_{2}
$$

Recently, the determination of superoxide dismutase (SOD) activity has been the object of much research work [1]; the greatest complication arises from the nature of the substrate, the superoxide radical, $\mathrm{O}_{2}^{-}$, which dismutes spontaneously and is not easily produced.

Spectrophotometric assays are the most commonly used [2-10]; the procedures are based on the inhibitory effects of SOD on the autoxidation of various chemicals in aqueous solution. Electrochemical probes have been used in numerous assays of metabolites of clinical and biochemical interest [11-13] and have been also proposed for the determination of SOD activity [14]. 
In this paper, an electrochemical probe, the oxygen sensor, is applied in a flow-through system to follow the autooxidation of pyrogallol, 6-hydroxydopamine, epinephrine and catechol. It is well known that in such reactions the superoxide radical is formed and that the level of oxygen depends on the rate of superoxide dismutation. The introduction of SOD varies this rate, thus modulating the oxygen pressure, and a relationship is obtained between the oxygen level and the SOD activity. The oxygen probe is insensitive to other substances present in the sample so that such a system should be more attractive than those based on spectrophotometric measurements, even though it is less sensitive.

\section{EXPERIMENTAL}

\section{Materials and apparatus}

Superoxide dismutase (from bovine erythrocytes, lyophilized powder, 3000 $\mathrm{U} \mathrm{mg}^{-1}$; E.C. 1.15.1.1) was obtained from Sigma Chemical Company. The material was found to be $98 \%$ pure and the molecular weight was assumed to be 30000 [15]. All the buffer solutions, $0.1 \mathrm{M}$ phosphate, $0.1 \mathrm{M}$ and $0.05 \mathrm{M}$ Tris, $0.1 \mathrm{M}$ MOPS [3-( $N$-morpholino)propanesulfonic acid], 0.1 M HEPES ( $\mathrm{N}-2$ hydroxyethylpiperazine- $N^{\prime}$-2-ethanesulfonic acid), $0.05 \mathrm{M}$ glycine and $0.1 \mathrm{M}$ sodium carbonate, were equilibrated with air before use.

Pyrogallol solution $(0.1 \mathrm{M})$ was prepared daily in distilled water and suitably diluted. 6-Hydroxydopamine hydrochloride (2,4,5-trihydroxyphenylethylamine) and catechol (1,2-dihydroxybenzene) were obtained from Fluka. LEpinephrine (Fluka) solutions were prepared in diluted hydrochloric acid ( $\mathrm{pH}$ 2.0 ). This acidic solution was mixed in the flow system with the $0.1 \mathrm{M}$ carbonate buffer $(\mathrm{pH} 10.0)$ in a mixing coil $(50 \mathrm{~cm})$ before mixing with the enzyme solution. The $\mathrm{pH}$ of the reaction mixture did not change after the epinephrine addition.

All other chemicals (analytical grade) were used without any special precaution.

The oxygen probe (Idronaut, Milan) was used in conjunction with an oxygen analyzer (Oxyliquid Model 23, Idronaut) which was connected to a Linseis L-6512 recorder. The oxygen probe was placed in a flow cell thermostated at $25.0 \pm 0.1^{\circ} \mathrm{C}$. A peristaltic pump (Carlo Erba Strumentazione, Milan; model PP8) was used to provide flow rates of 0.2 and $2 \mathrm{ml} \mathrm{min}^{-1}$.

\section{Procedure}

The SOD activity was assayed under flow conditions. The flow system is outlined in Fig. 1(a); a typical response of the oxygen probe is shown in Fig. 1 (b). Buffer (B) is pumped by the peristaltic pump (P) at a rate of $2 \mathrm{ml} \mathrm{min}^{-1}$ and mixed, through the 3-way tap 1 , with distilled water (W) so that a steadystate current is obtained (line A, Fig. 1b). At time B (Fig. 1b), tap 1 is turned 

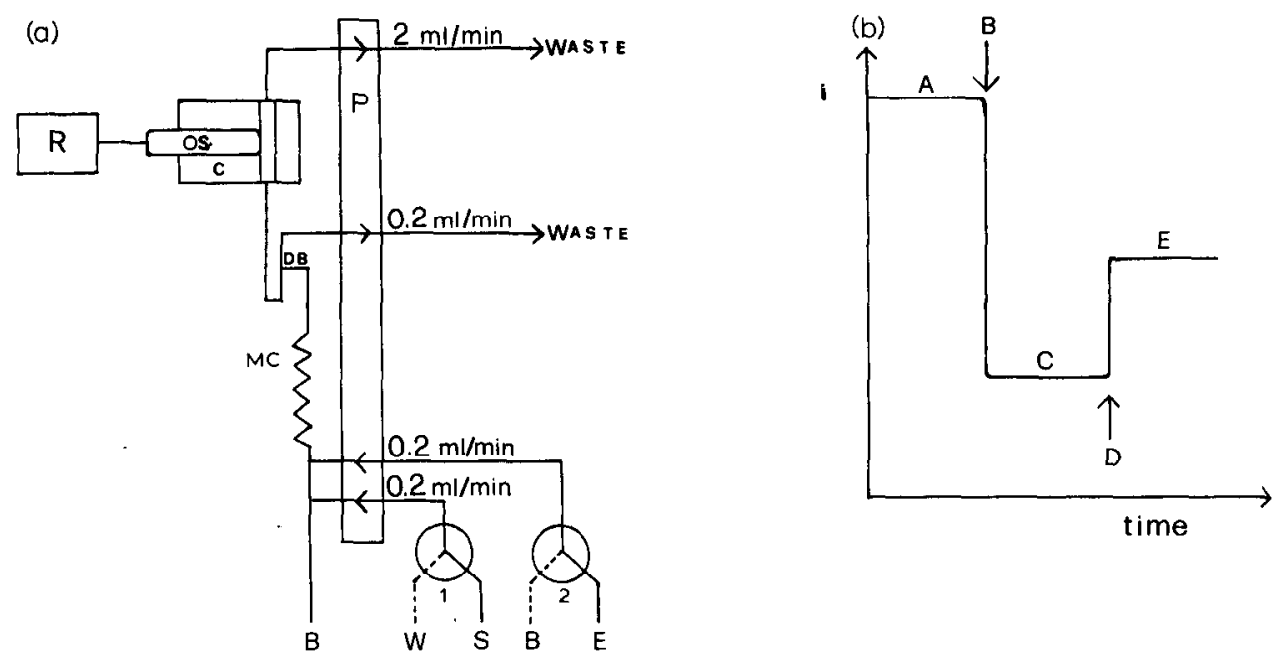

Fig. 1. (a) Schematic diagram of the flow system. (b) Response of the apparatus. See text for detail.

so that the aqueous solution (S) of pyrogallol (or other substrate) is pumped and mixed with the buffer in a coil (MC) of prefixed length $(50$ or $100 \mathrm{~cm}$, see below); the substrate consumes the dissolved oxygen, producing superoxide ions. The mixture passes into the cell $(\mathrm{C})$ holding the oxygen sensor (OS) attached to recorder $R$. The oxygen probe monitors the oxygen pressure until a new steady state is attained (line C, Fig. $1 \mathrm{~b}$ ). At time D, a SOD solution in buffer (E, Fig. 1a) is pumped through the 3-way tap 2. In the presence of SOD, the superoxide dismutation rate is enhanced and the oxygen concentration in cell $\mathrm{C}$ is higher. The probe reaches a new steady state (line E, Fig. 1b).

Before the flow stream enters cell C, a debubbler (DB) is necessary to remove spurious air bubbles, which affect the reproducibility of the steady state.

\section{RESULTS AND DISCUSSION}

The advantage of the apparatus and procedure described is the high reproducibility of the autooxidation of the substrates obtained and the reliability of the highly selective electrochemical measurement of the oxygen concentration. The kinetic behaviour is highly complex because of the labile nature of the superoxide ion but, with the procedure and manifold described, as little as $0.3 \%$ of the oxygen saturation level can be monitored; the noise corresponds to about $0.1 \%$ of the oxygen saturation level. The effect of SOD can thus be monitored easily and the calibration curves of the percentage decrease in the oxygen saturation level as a function of the SOD activity are very reproducible.

The possibility of analyzing several samples within a few minutes is of in- 
terest, and the possibilities of varying the reaction parameters by means of the stopcocks, flow rates and coil length make the system highly flexible.

Several substrates were examined for the generation of the superoxide radical through autooxidation. The results obtained are described below.

\section{Pyrogallol}

Pyrogallol autooxidizes rapidly in aqueous solution; the higher the $\mathrm{pH}$, the faster the process. Several intermediate products are apparently formed. The solution first becomes yellow-brown and yellow after several minutes; the rate of oxygen consumption increases with $\mathrm{pH}$. Figure 2 shows the variation of oxygen pressure as a function of pyrogallol concentration for several lengths of reaction coil (a) and as a function of $\mathrm{pH}$ and buffer at two pyrogallol concentrations (b). The oxygen percentage reported on the ordinate is related to the oxygen saturation level measured at the beginning of the experiment and taken as $100 \%$. From Fig. 2 , it can be seen that as the $\mathrm{pH}$ is raised, the oxygen consumption increases; at $\mathrm{pH}>8.5$ it is necessary to decrease the pyrogallol concentration so that the reaction can be studied within the measurable range of oxygen concentration.

It can also be seen that the phosphate buffer inhibits the pyrogallol reaction at pH 7.0-7.5; with MOPS and HEPES buffers (data not shown), the results obtained were similar to those with Tris.

Figure 3 shows the calibration curves of the oxygen-probe current as a function of the SOD concentration at different $\mathrm{pH}$ values and different pyrogallol concentrations. Different ranges of SOD activity can be covered at the three $\mathrm{pH}$ values. At $\mathrm{pH} 7.5$, the minimum amount of SOD detectable is $5 \times 10^{-8} \mathrm{M}$;
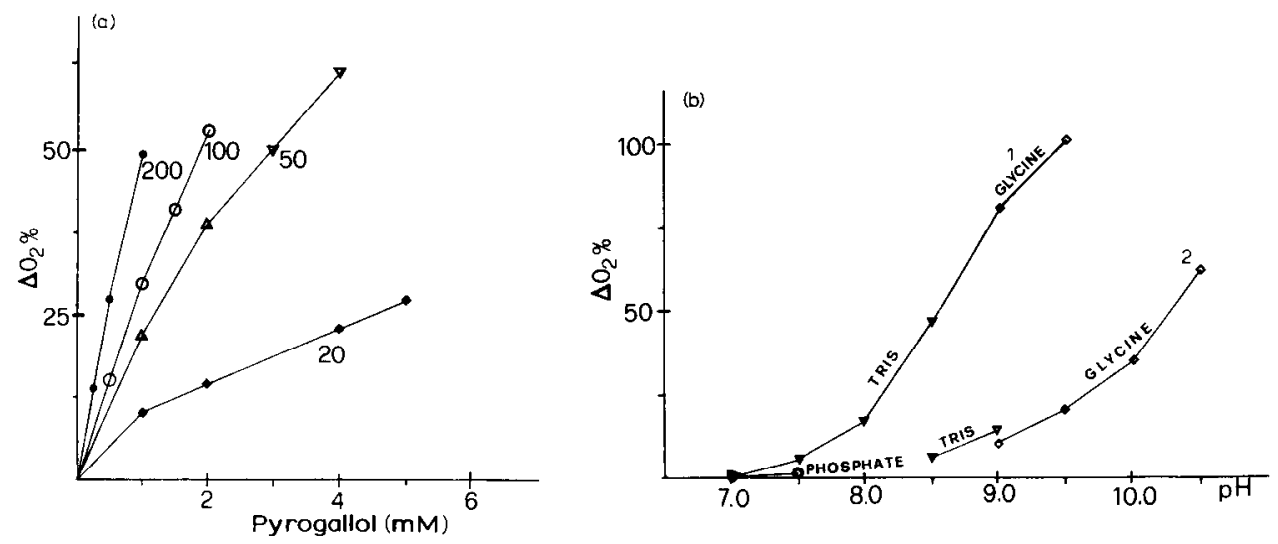

Fig. 2. Oxygen consumption caused by the extent of autooxidation of pyrogallol: (a) as a function of pyrogallol concentration and coil length (given on the curves in $\mathrm{cm}$ ) in $0.1 \mathrm{M}$ Tris buffer $\mathrm{pH}$ 8.5 ; (b) as a function of the $\mathrm{pH}$ and buffer for pyrogallol concentrations of $2 \times 10^{-3} \mathrm{M}$ (curve 1) and $2 \times 10^{-4} \mathrm{M}$ (curve 2 ). 

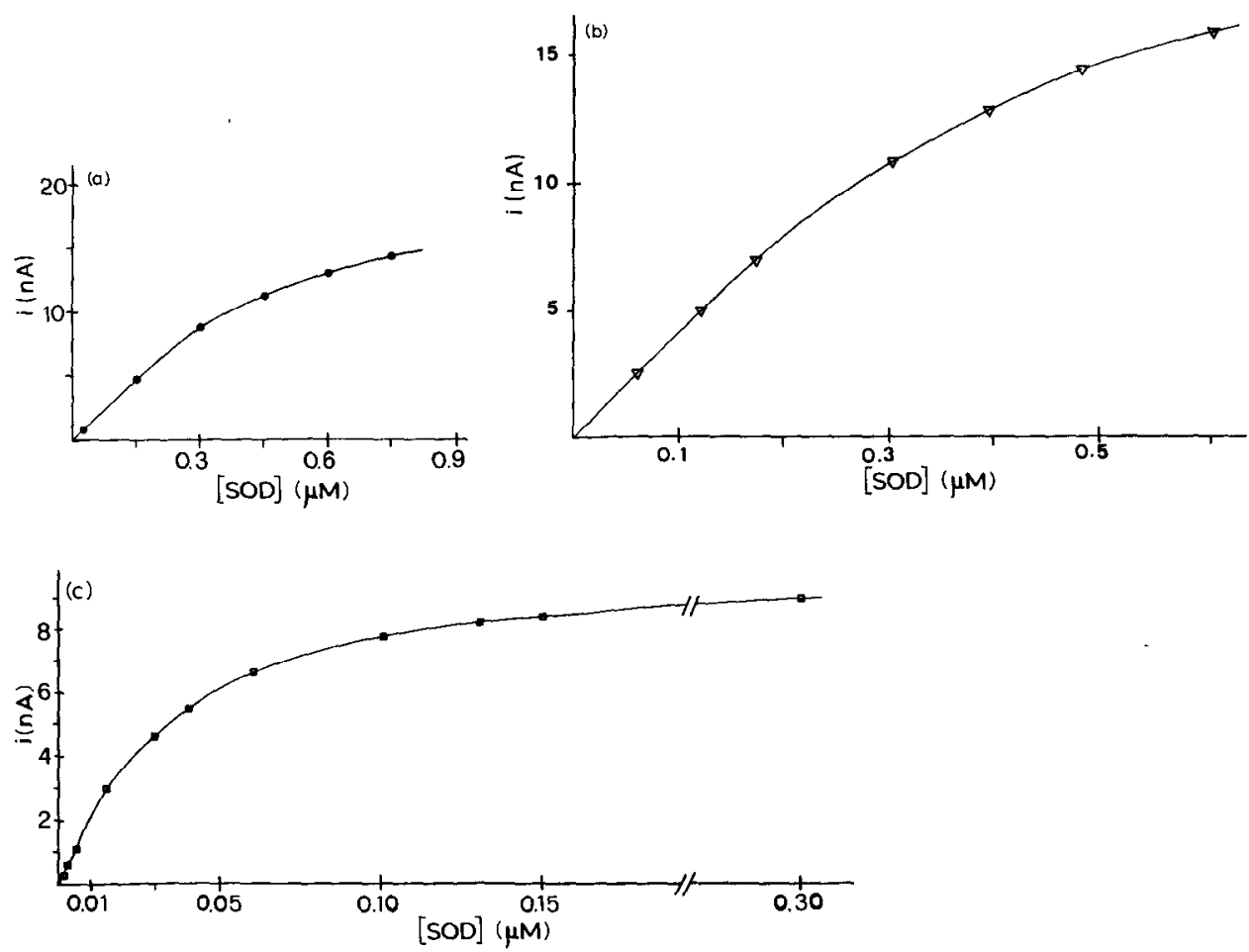

Fig. 3. Calibration curves for SOD concentration with pyrogallol as substrate (coil length $50 \mathrm{~cm}$ ): (a) $0.1 \mathrm{M}$ Tris buffer $\mathrm{pH} 7.5,2 \mathrm{mM}$ pyrogallol; (b) $0.1 \mathrm{M}$ Tris buffer $\mathrm{pH} 8.5,2 \mathrm{mM}$ pyrogallol; (c) $0.1 \mathrm{M}$ glycine buffer $\mathrm{pH} 9.5,0.5 \mathrm{mM}$ pyrogallol.

at $\mathrm{pH} 9.5$ the minimum is $1.5 \times 10^{-9} \mathrm{M}$. All three calibration graphs in Fig. 3 become straight lines when the data are plotted as $i^{-1}$ vs. $c^{-1}$, where $c$ is the SOD concentration. For all the $\mathrm{pH}$ values, the correlation coefficients of such plots were $\geqslant 0.999$. Of course, from the analytical point of view, the calibration plots reported in Fig. 3 are preferable because the range in which the SOD activity can be determined with better precision is easily seen from the slopes of the curves.

Figure 4 shows how the inhibition of the autooxidation reaction caused by $S O D$ varies with $\mathrm{pH}$. In all cases, the SOD concentration was very high $\left(1 \times 10^{-6}\right.$ $M)$; inhibition was calculated as the ratio between the oxygen variation caused by SOD autooxidation and the oxygen variation caused by autooxidation of the substrate. It is known [2] that there are two different mechanisms of autooxidation in the $\mathrm{pH}$ interval investigated. The mechanism predominating at $\mathrm{pH} 9.0$ involves the superoxide ion as a chain-propagating species; at higher $\mathrm{pH}$, the mechanism does not depend on superoxide ion. From Figs. 3 and 4, this is evident because the \% inhibition of the autooxidation reaction gradually 


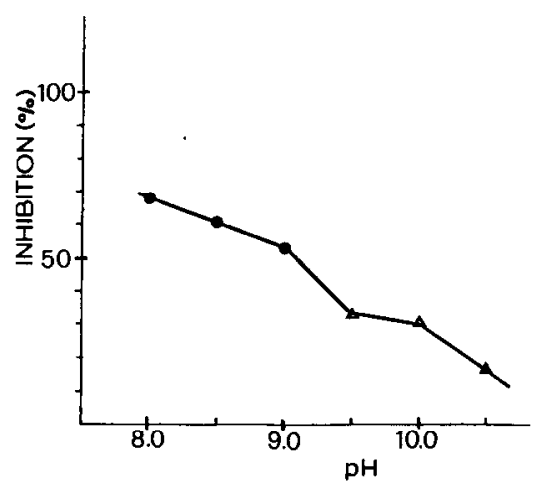

Fig. 4. Maximum inhibition of pyrogallol autooxidation determined with SOD as a function of pH. Conditions: $1 \mu \mathrm{M}$ SOD; 50-cm coil; pyrogallol concentration, $2 \mathrm{mM}$ for $\mathrm{pH}$ 8.0-9.0, $1 \mathrm{mM}$ for pH 9.5, $0.5 \mathrm{mM}$ for $\mathrm{pH} 10.0$, and $0.25 \mathrm{mM}$ for $\mathrm{pH} 10.5$.

decreases with increasing $\mathrm{pH}$; but because the extent of autooxidation increases with $\mathrm{pH}$, the assay is more sensitive at higher $\mathrm{pH}$ values (9.5).

EDTA has been reported [2,7] to retard the autooxidation of pyrogallol and to increase the activity of SOD by complexing traces of metal ions. In preliminary experiments, no evidence was found for this phenomenon with EDTA concentrations up to $1 \mathrm{mM}$; therefore, EDTA was not added in this study.

\section{6-Hydroxydopamine}

6-Hydroxydopamine (6-OHDA) reacts spontaneously with oxygen to form one molecule each of quinone and hydrogen peroxide. It has been shown [4] that during the autooxidation of 6-OHDA, superoxide ion is formed and catalyzes the further autooxidation of 6-OHDA. Accordingly, 6-OHDA was tested as a substrate for SOD with the flow apparatus previously described. Figure 5 reports the extent of autooxidation as functions of 6-OHDA concentration (a) and $\mathrm{pH}(\mathrm{b})$. Comparison with results obtained for pyrogallol (Fig. 2) shows that the extent of autooxidation is higher with 6-OHDA and that it is less pHdependent. The inhibitory effect of phosphate reported for pyrogallol is not evident, but the Tris buffer is more suitable for autooxidation because the percentage of oxygen consumed is higher at the same substrate concentration. The inhibition by SOD (Fig. 6 ) is similar with both buffers. The sharp decrease of the inhibitory effect of SOD at $\mathrm{pH}>8$ was not observed with pyrogallol (Fig. 4 ); at $\mathrm{pH} \mathrm{9.5,} \mathrm{the} \mathrm{inhibition} \mathrm{of} \mathrm{autooxidation} \mathrm{of} \mathrm{6-OHDA} \mathrm{by} \mathrm{SOD} \mathrm{is} \mathrm{less} \mathrm{than}$ $10 \%$ whereas it is still $30 \%$ with pyrogallol; even at $\mathrm{pH} 10.5$ with pyrogallol, inhibition is $>15 \%$. This result is contrary to an earlier report [4].

The above results show that under the present experimental conditions the extent of autooxidation at $\mathrm{pH}>8$ is about the same, while the inhibitory effect of SOD decreases. At $\mathrm{pH} \mathrm{7.4,} \mathrm{a} \mathrm{compromise} \mathrm{is} \mathrm{obtained,} \mathrm{which} \mathrm{is} \mathrm{suitable} \mathrm{for}$ analytical purposes; the autooxidation is still high (much more than with py- 

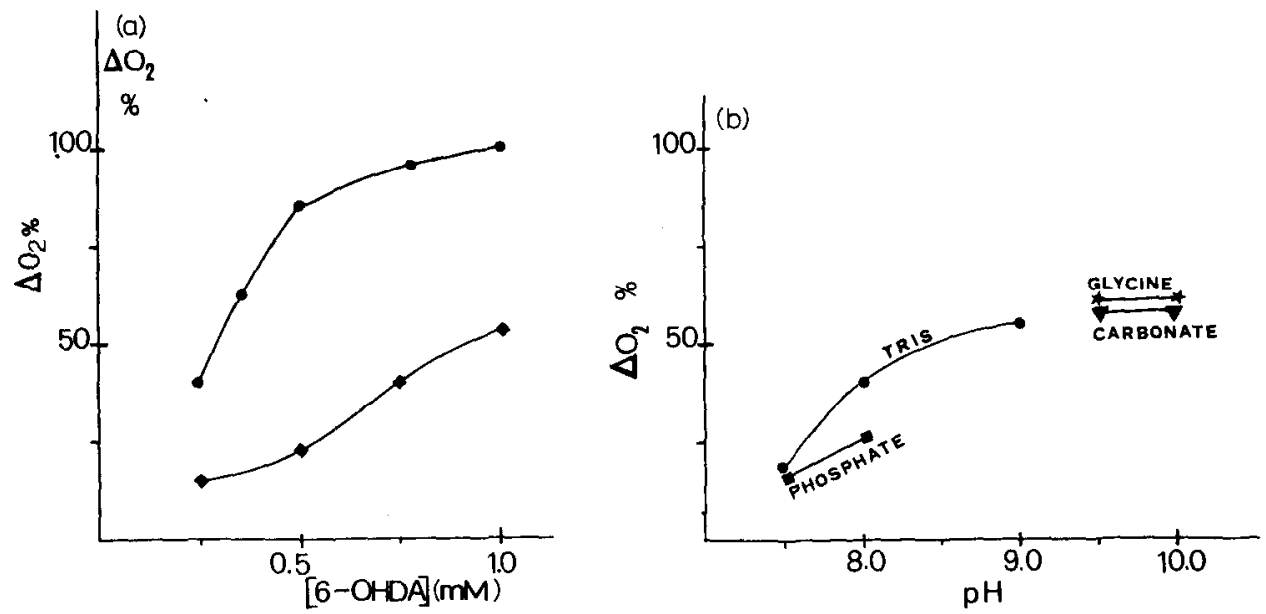

Fig. 5. Oxygen consumption caused by autooxidation of 6-OHDA: (a) as a function of the concentration in $0.05 \mathrm{M}$ phosphate buffer $\mathrm{pH} 7.4(\diamond)$ or in $0.05 \mathrm{M}$ Tris buffer $\mathrm{pH} 8.0(0)$; (b) as a function of buffer and $\mathrm{pH}$ for $1.0 \mathrm{mM}$ 6-OHDA. Coil length $100 \mathrm{~cm}$.

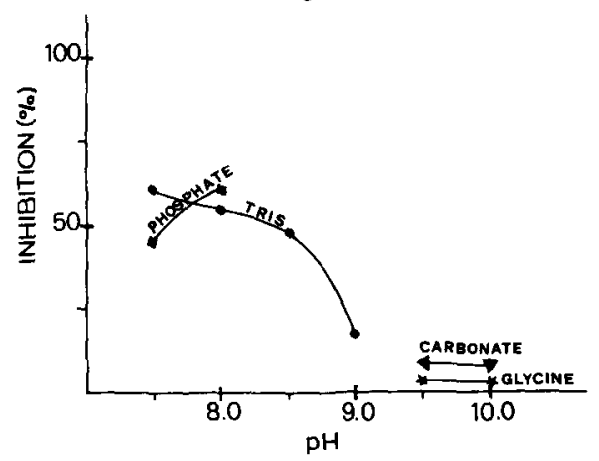

Fig. 6. Maximum inhibition of 6-OHDA autooxidation by $\mathrm{SOD}$ as a function of $\mathrm{pH}$ and buffer. Conditions: $1 \mu \mathrm{M}$ SOD, $0.25 \mathrm{mM}$ 6-OHDA, coil length $100 \mathrm{~cm}$.

rogallol), and the inhibitory effect of SOD is amplified. The calibration curve is shown in Fig. $7(\mathrm{a}) ; 2 \times 10^{-10} \mathrm{M}$ SOD can be detected. These results are of interest as the $\mathrm{pH}$ is near physiological values. At higher $\mathrm{pH}$ (Fig. 7b, c), the sensitivity decreases substantially as expected from Figs. 5 and 6. Plots of $i^{-1}$ vs. $c^{-1}$ are straight lines with correlation coefficients of about 0.998 .

\section{Epinephrine}

The autooxidation of epinephrine has already been exploited for the determination of SOD activity $[7,8]$. In preliminary tests with the present flow system, it was found that autooxidation of epinephrine was $\leqslant 5 \%$ even at $\mathrm{pH}$ 10.5. However, the autooxidation reaction has a low kinetic constant [8]. Therefore, the flow system was modified by inserting a coil where the mixture 

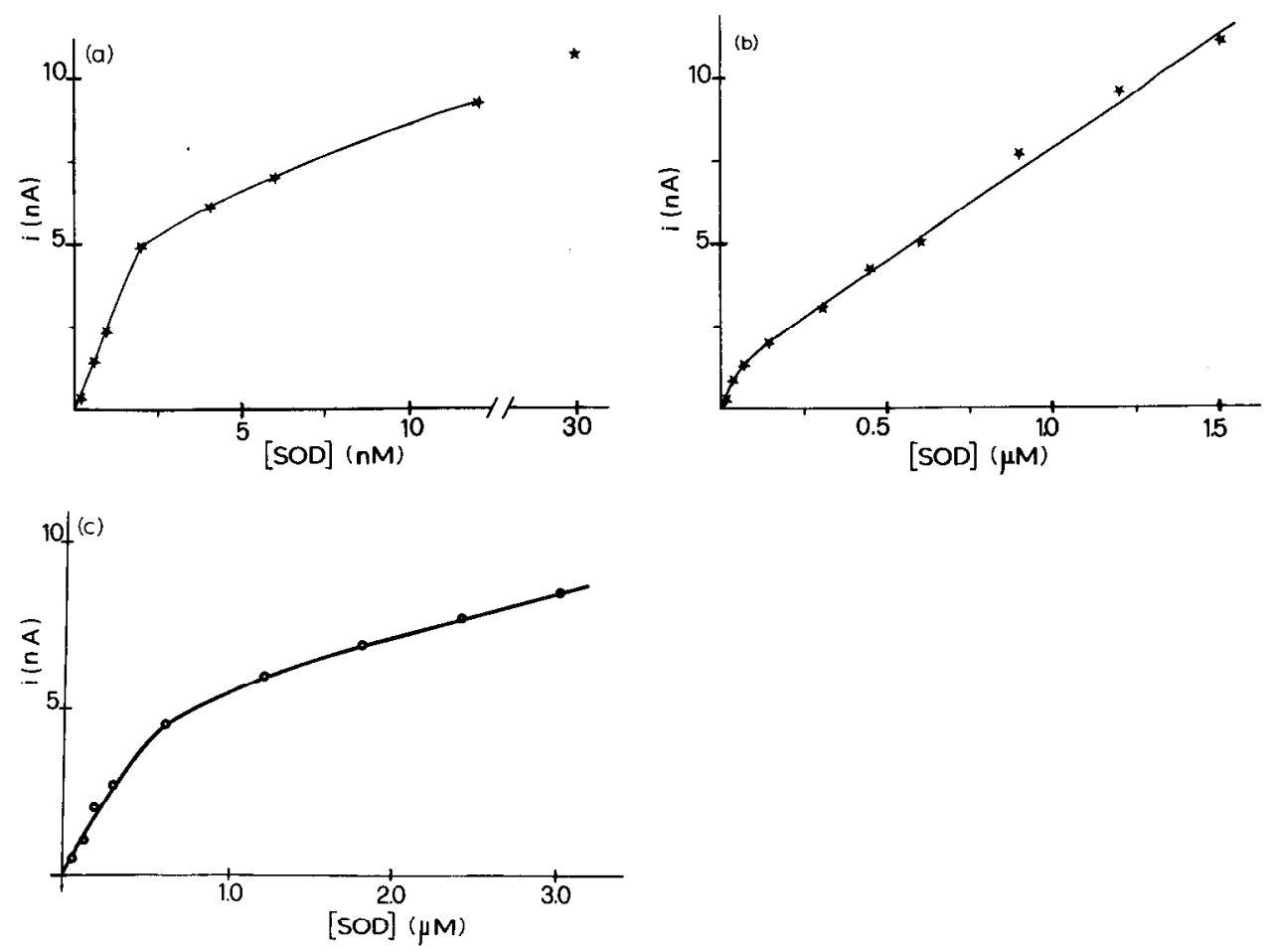

Fig. 7. Calibration curves for SOD concentration in different buffers: (a) $0.05 \mathrm{M}$ phosphate $\mathrm{pH}$ 7.4, 0.05 mM 6-OHDA; (b) 0.05 M Tris pH 8.5, 0.25 mM 6-OHDA; (c) $0.05 \mathrm{M}$ carbonate pH 9.5, $0.25 \mathrm{mM}$ 6-OHDA. Coil length $100 \mathrm{~cm}$.

of substrate and aerated buffer could remain for a longer time for autooxidation to take place. Insertion of another valve enabled the aerated buffer to flow past the oxygen probe during this time. After a suitable time, this valve was switched so that the "slug" was inserted into the flow stream; the recorded signal was then not a steady-state value but a narrow peak corresponding to the decreased oxygen content. When the coil was filled with different amounts of SOD, the decrease in peak height depended on the activity in the final solution. Figure 8 shows the peak heights for two epinephrine concentrations as a function of residence time in the reaction coil.

When the residence time was $8 \mathrm{~min}$ and the substrate concentration was $2 \times 10^{-3} \mathrm{M}$, the calibration curve for SOD activity in $0.1 \mathrm{M}$ carbonate buffer at $\mathrm{pH} 10$ was as reported in Fig. 9. The variation of current produced was greater than those obtained with pyrogallol and 6-OHDA at the same $\mathrm{pH}$ but the general behaviour of current vs. SOD concentration was similar. However, the peak measurements ( $2 \% \mathrm{RSD}$ ) were less reproducible than the steadystate values obtained with the other substrates $(0.3 \% \mathrm{RSD})$. This was reflected in the correlation coefficients obtained for reciprocal plots $(0.96-0.97)$, 


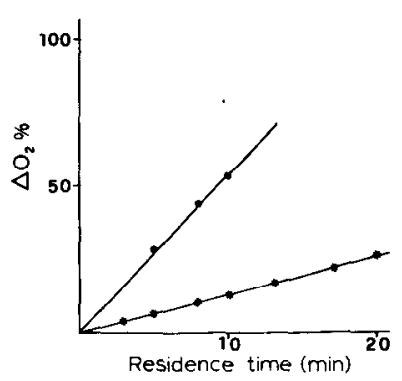

Fig. 8. Oxygen consumption by epinephrine autooxidation as a function of residence time. Epinephrine concentration: $\left(^{*}\right) 0.2 \mathrm{mM}$; (०) $2 \mathrm{mM}$.

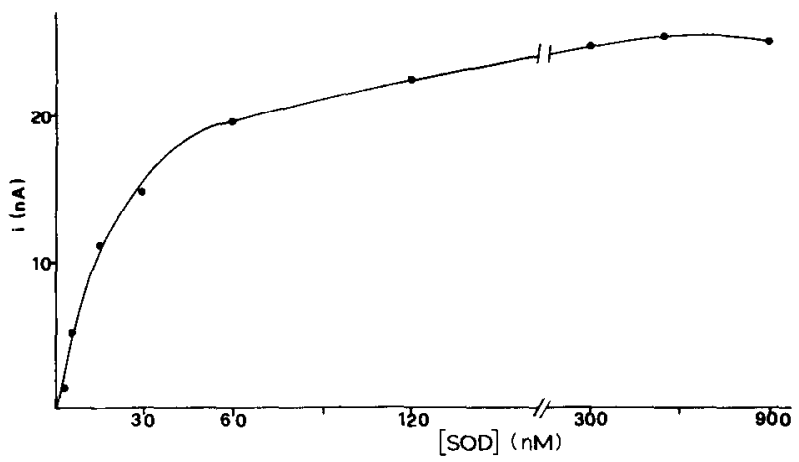

Fig. 9. Calibration curve of SOD activity with $2 \mathrm{mM}$ epinephrine as substrate in $0.1 \mathrm{M}$ carbonate buffer at $\mathrm{pH} 10.0$.

which were even worse for $i$ vs. $\log c$ plots (0.992). Moreover, from the practical point of view, the time needed to obtain a peak was about 5 times the time needed for a steady-state measurement.

\section{Catechol}

When catechol was used as substrate in the flow system (Fig. 1), no decrease of oxygen was observed in the $\mathrm{pH}$ range 7.4-8.5; in the $\mathrm{pH}$ range 9-10.5, autooxidation was only slight, increasing with $\mathrm{pH}$ and catechol concentration. The oxygen consumption was very poor compared to the results obtained with pyrogallol and 6-OHDA. When catechol $\left(10^{-3} \mathrm{M}\right)$ was tested in the modified flow system, as described for epinephrine, with a carbonate buffer $\mathrm{pH} 10$, a residence time of $5 \mathrm{~min}$ produced a sharp increase in the oxygen consumption from $2 \%$ to about $50 \%$. However, even a high concentration $\left(10^{-5} \mathrm{M}\right)$ of SOD did not show any inhibitory effect on the oxygen consumption at any substrate concentration or $\mathrm{pH}$. This substrate was not examined further. 


\section{REFERENCES}

1 J.V. Bannister and L. Calabrese, in D. Glick (Ed.), Methods of Biochemical Analysis, Vol. 32, Wiley-Interscience, New York, 1987, p. 279.

2 S. Marklund and G. Marklund, Eur. J. Biochem., 47 (1974) 469.

3 W.-J. Li, F. Cheng and W.-T. Wu, Acta Biochem. Biophys. Sin., 18 (1986) 185.

4 R.E. Heikkila and G. Cohen, Science, 181 (1973) 456.

5 R.E. Heikkila and F. Cabbat, Anal. Biochem., 75 (1976) 356.

6 G. Cohen and R.E. Heikkila, J. Biol. Chem., 249 (1974) 2447.

7 H.P. Misra and I. Fridovich, J. Biol. Chem., 217 (1972) 3170.

8 M. Sun and S. Zigman, Anal. Biochem., 90 (1978) 81.

9 Y. Kono, Arch. Biochem. Biophys., 186 (1978) 189.

10 C. Auclair, M. Torres and J. Hakim, Febs. Lett., 89 (1978) 26.

11 G.G. Guilbault, Analytical Uses of Immobilized Enzymes, M. Dekker, New York, 1984.

12 M. Mascini and G.G. Guilbault, Biosensors 2 (1986) 147.

13 M. Mascini, F. Mazzei, D. Moscone, G. Calabresi and M. Massi-Benedetti, Clin. Chem., 33 (1987) 591.

14 A. Rigo, P. Viglino and G. Rotilio, Anal. Biochem., 68 (1975) 1.

15 H.M. Steinman, in L.W. Oberley .(Ed.), Superoxide Dismutase, Vol. 1, CRC Press, Boca Raton, FL, 1982, Chap. 2, Table 1. 